Supporting Information for:

\title{
A novel ultrasensitive electrochemical biosensor of bacterial 16S rRNA gene based on polyA DNA probes
}

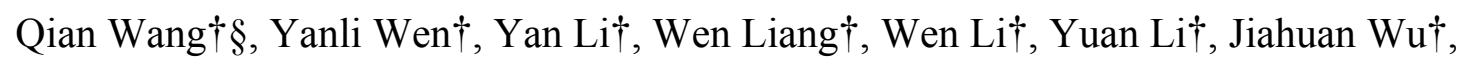
Huichen Zhu†, Keke Zhao $\dagger$, Jun Zhang $\dagger$, Nengqin Jia§*, Wangping Dengt//*, Gang Liu†*

'Laboratory of Biometrology, Shanghai Institute of Measurement and Testing Technology, 1500 Zhang Heng Road, Shanghai 201203, People's Republic of China

$\S$ Department of Chemistry, College of Chemistry and Materials Science, Shanghai Normal University, 100 Guilin Road, Shanghai 200234, China

¥ National Institute of Parasitic Diseases, Chinese Center for Disease Control and Prevention, 207 Rui Jin Er Road, Shanghai 200025, China.

"Chinese Center for Tropical Diseases Research, 207 Rui Jin Er Road, Shanghai 200025, China.

Characterization of the polyA-based SAM on electrode array, Optimization of reporter probe concentration, Optimization of the hybridization temperature, The study of the reaction temperature between avidin-HRP and the reporter probes, Digital PCR results of the St genome DNA quantification 


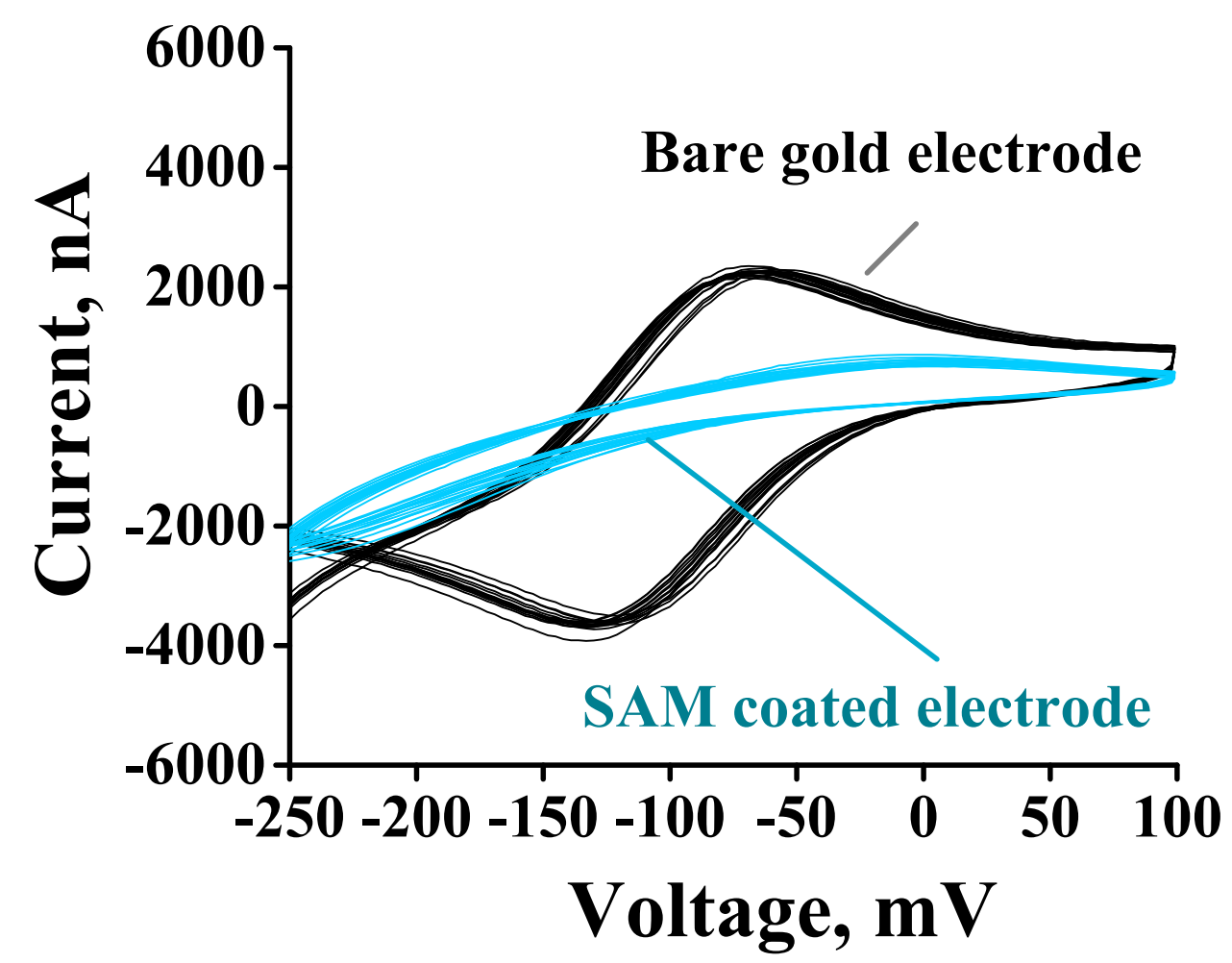

Figure S1, Characterization results of the electrode array before (black lines) and after (blue lines) the assembling of polyA probe and $\mathrm{MCH}$. $\mathrm{CV}$ test was performed in $0.5 \mathrm{mM}$ potassium ferricyanide solution containing $1 \mathrm{M} \mathrm{KCl}$.

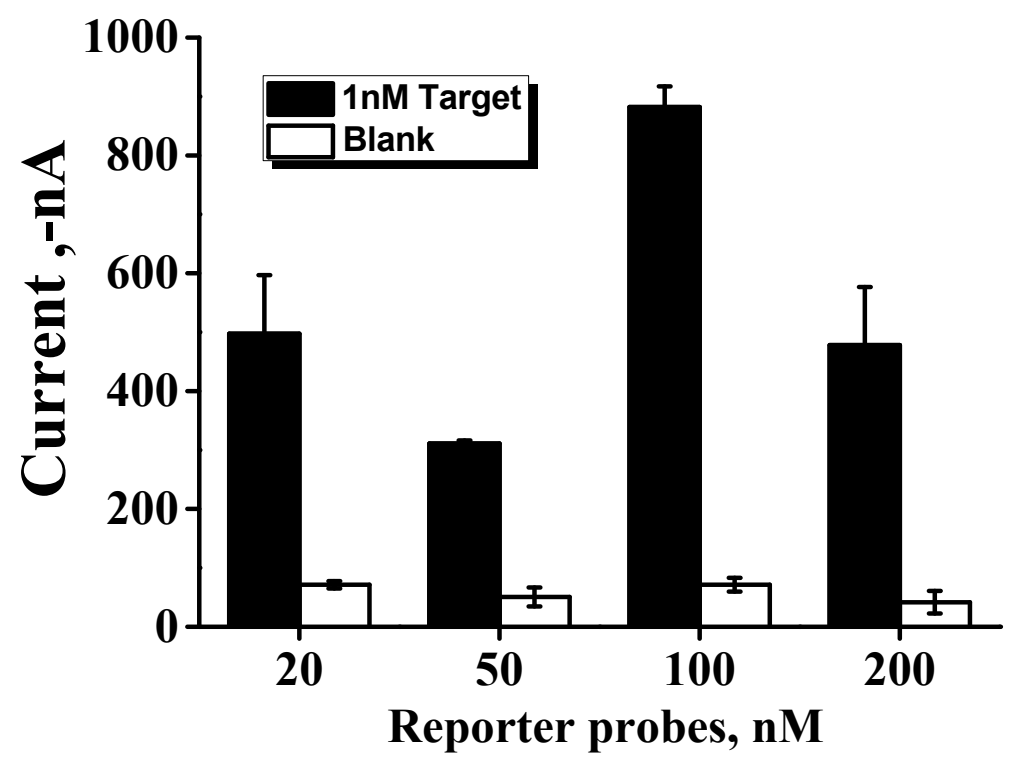

Figure S2, optimization of reporter probes (RPs) concentration. When the concentration of RPs was $100 \mathrm{nM}$, we achieved the highest signal-to-noise $(\mathrm{S} / \mathrm{N})$. The 2-reporter-probe (RP2) system was applied in this experiment, and the concentration 
of the St target DNA was $1 \mathrm{nM}$.

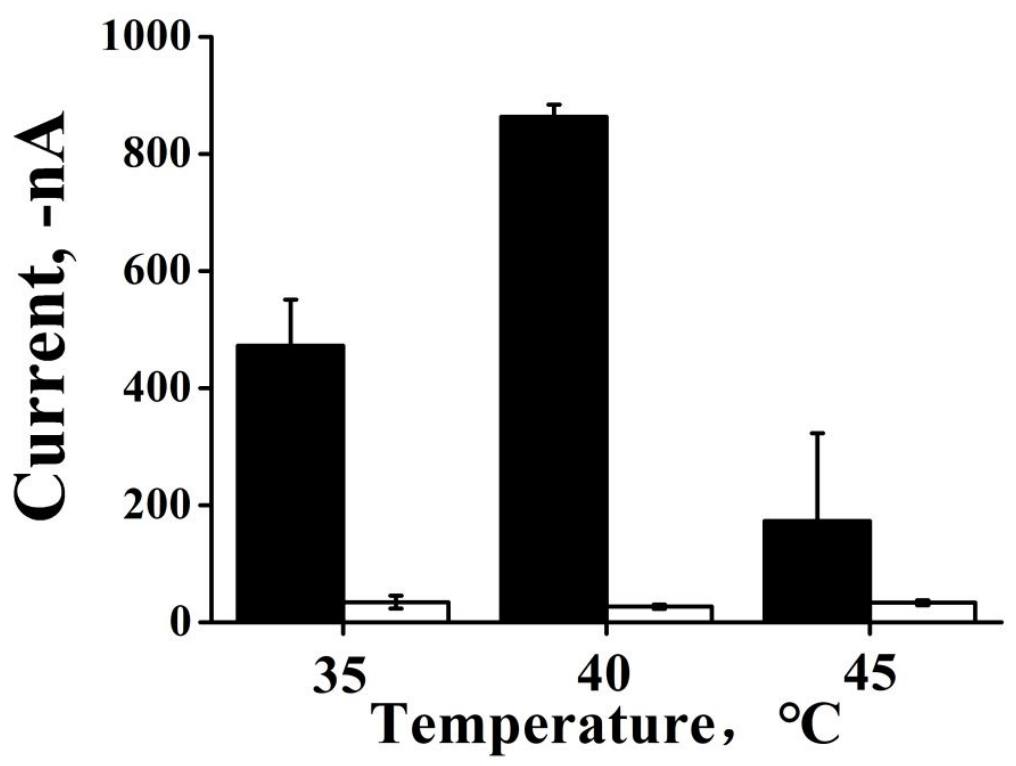

Figure S3, optimization of the reaction temperature for the hybridization between the capture probe and the pre-hybridized complex (target and 2 reporter probes). When $35^{\circ} \mathrm{C}, 40^{\circ} \mathrm{C}$, and $45^{\circ} \mathrm{C}$ was used, the $\mathrm{S} / \mathrm{N}$ was $13.6,32.0$, and 5.1 , respectively. Thus, $40{ }^{\circ} \mathrm{C}$ was proved the best hybridization temperature. The concentration of the St target DNA was $1 \mathrm{nM}$, in this experiment.

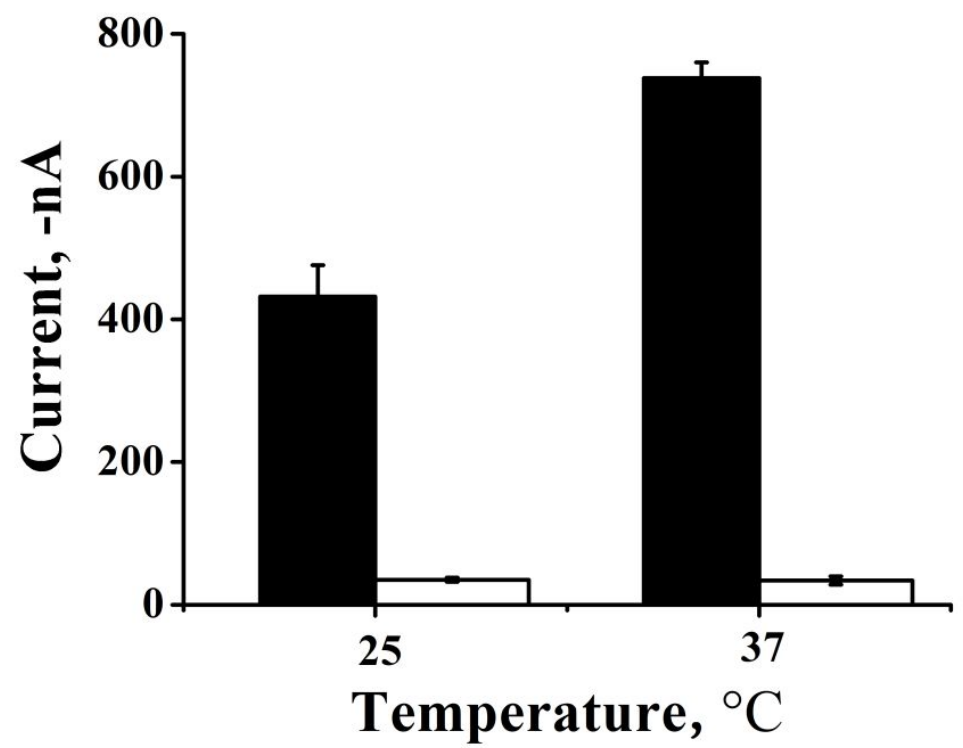

Figure S4, the study of the reaction temperature for the combination between avidin-HRP and the reporter probes. When $35{ }^{\circ} \mathrm{C}$ and $37{ }^{\circ} \mathrm{C}$ was used, the corresponding $\mathrm{S} / \mathrm{N}$ was 12.3 and 21.7. The concentration of the St target DNA was 1 
$\mathrm{nM}$, in this experiment.
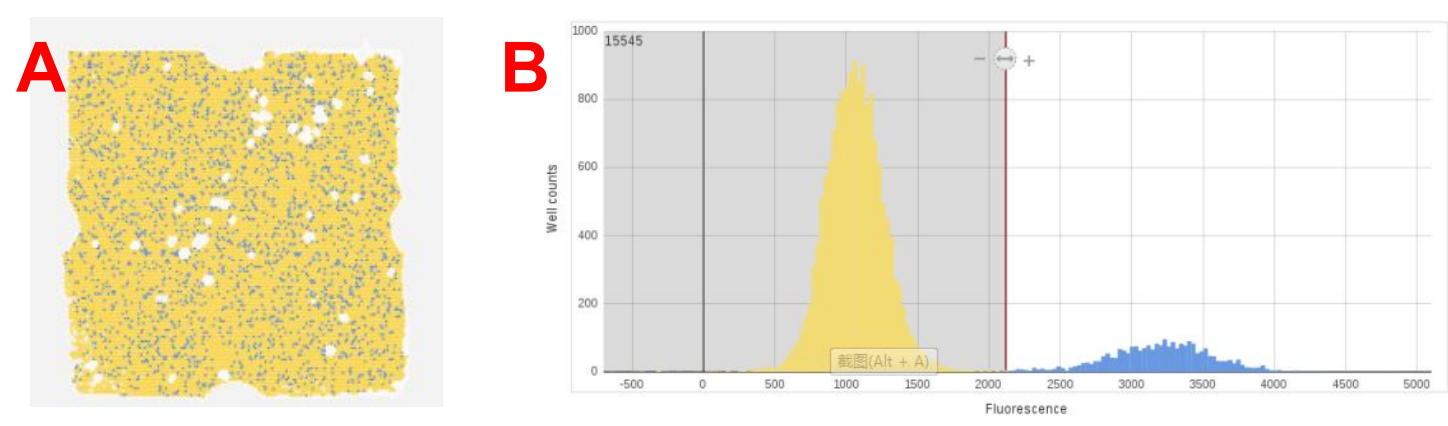

Figure S5, digital PCR quantification results of the St genome DNA. A) chip view results: the yellow dots represent negative wells and the blue dots represent positive wells; B) corresponding fluorescence distribution for each results. the yellow peak showed the number of wells below the fluorescence threshold (negative PCR reactions), while the blue peak showed the number of wells above the fluorescence threshold (positive PCR reactions), and the red vertical line is the fluorescence threshold line. 